\title{
Conocimientos y saberes de los profesores de primaria sobre la conquista de México: una exploración a través de la lectura de fuentes históricas
}

Lic. Geovanny Bello Cortés, Mexicano.

ORCID: 0000-0003-3240-888X

geovannybello0@gmail.com

Adscrito a la Escuela Primaria "Juan José Arreola",

CCT: 15DPR3280T, Zona Escolar: 076, Sector II, Subdirección Atlacomulco.

Lic. Gerardo Morales García, Mexicano.

ORCID: 0000-0002-9860-1394

janomoga@gmail.com

Adscrito a 0FTV 0240 “5 de Febrero”, CCT: 15ETV0238H, Zona V022, Subdirección 06 Toluca

Recibido: 18 de septiembre del 2020

\section{Resumen}

Aceptado: 10 de octubre del 2020

Este artículo tiene como propósito explorar a través de la lectura de fuentes históricas los conocimientos previos de los docentes de educación primaria ¿Qué genera en el docente el confrontar sus saberes con información que pueda cuestionar sus conceptos? Se aplicaron estrategias de introspección a un grupo de docentes de cuarto y sexto grado de educación primaria. La primera estrategia, Visualización de conceptos, permitió registrar gráficamente el saber inicial del maestro respecto al tema de la conquista de México y los conceptos a) conquista militar y b) conquista espiritual. La segunda, La proyección, consistió en la presentación de una selección de fragmentos sobre el mismo tema utilizando fuentes históricas con distintas versiones historiográficas. El ejercicio provocó un dialogo entre los profesores, donde se suscitaron comentarios altamente significativos sobre reconstruir y resignificar sus conceptos y modificar su labor docente para favorecer el aprendizaje de la historia en los niños.

Palabras clave: Fuentes escritas, formación docente, conquista de México 


\title{
Knowledge and knowledge of primary school teachers about the conquest of Mexico: an exploration through the Reading of historical source
}

\begin{abstract}
The purpose of this article is to explore through the reading of historical sources the previous knowledge of primary education teachers. What does it generate in the teacher to confront their knowledge with information that can question their concepts? Introspection strategies were applied to a group of fourth and sixth grade primary school teachers. The first strategy, Visualization of concepts, allowed to graphically record the initial knowledge of the teacher regarding the subject of the conquest of Mexico and the concepts a) military conquest and b) spiritual conquest. The second, La projection, consisted of the presentation of a selection of fragments on the same topic using historical sources with different historiographic versions. The exercise provoked a dialogue between the teachers, where highly significant comments were raised about reconstructing and resignifying their concepts and modifying their teaching work to favor the learning of history in children.
\end{abstract}

Keywords: Written sources, teacher training, conquest of Mexico

\section{Introducción}

El trabajo docente en educación primaria tiene, como uno de sus principales rasgos, el ser una práctica multidisciplinar, es decir, el maestro aborda contenidos de diferentes asignaturas académicas en un tiempo escolar determinado. Del mismo modo que imparte saberes de matemáticas, geografía; también aborda temas de historia, formación cívica, educación física, español, y en ocasiones hasta de inglés.

A través de su formación en las escuelas normales y en las universidades formadoras de profesores, el docente de educación básica recibe los elementos teórico-metodológicos para trabajar en un salón de clases como responsable del aprendizaje de los niños en edad escolar. Dentro de la formación didáctica, pocas veces se profundiza respecto al conocimiento histórico propio del docente. Es el propio educador, quien a partir de sus necesidades cognitivas deberá de indagar en varias fuentes de información para los temas que impartirá en el aula, vinculando dicho saber con los conocimientos que durante su formación escolar ha ido construyendo; o dicho en palabras de Barrón (2006): 
“...lo que saben los docentes sobre la enseñanza, proviene de su experiencia como alumnos y a partir de ésta construyen y reconstruyen sus prácticas en el aula, a través de un permanente movimiento de continuidad y rupturas con las teorías y perspectivas... los saberes que fundamentan la enseñanza son existenciales, sociales y pragmáticos. Son existenciales porque involucran a los seres humanos en su totalidad, con sus anhelos, sus deseos, sus emociones, sus relaciones con los otros y consigo mismo; sociales, provenientes de distintos núcleos y tiempos de formación escolar y de la vida cotidiana, por último son pragmáticos porque aluden a las experiencias y prácticas en el marco de las instituciones escolares y a las interacciones con los distintos actores."

Durante su formación, en escuelas normales o universidades, los profesores, rara vez se enfrentan a la necesidad de revisar sus saberes; los conocimientos adquiridos en su educación básica, y media superior o normal elemental en algunos casos, constituyen la base de su saber, la que a su vez, respaldará su didáctica en el salón de clases.

Algunos maestros, buscan por cuenta propia el allegarse de recursos bibliográficos o audiovisuales que enriquezcan su conocimiento en las diferentes asignaturas del programa de estudio. Del mismo modo, son pocos los docentes que realizan estudios de posgrado o que toman cursos por iniciativa propia para fortalecer sus aprendizajes. Cuando participan en cursos impartidos por la estructura educativa oficial, lo hacen obligados o condicionados para asistir; además, se trata de sesiones de trabajo en las que más allá de construir nuevos aprendizajes o consolidar otros, están diseñados para capacitar o actualizar al personal docente en la aplicación de las políticas educativas vigentes, lo que difiere en gran medida de los requerimientos para la formación profesional del maestro.

\section{Antecedentes}

En nuestro país, existen investigaciones importantes enfocadas a la problemática de la enseñanza histórica en la formación de docentes (Arteaga y Camargo, 2012) donde a partir de este análisis plantean como propuesta a "Educación Histórica", cuyo eje formativo es que los futuros profesores se doten de elementos para que comprendan la forma en que los historiadores hacen historia. Esta propuesta fue retomada por la Secretaria de Educación Pública para ser desarrollado en la formación de docentes a partir del 2012.En el centro de esta propuesta está la distinción entre los contenidos de la historia o procesos históricos, así como los significados específicos que adquieren algunos términos convencionales llamados también conceptos de primer orden o sustanciales, los 
cuales pueden ser "Independencia" "Revolución" "Estado", pero además se deben situar en un contexto especifico, es decir, en un tiempo y lugar. Y los de segundo orden, que se refieren a categorías analíticas que permitirán la comprensión como lo son tiempo histórico, cambio y permanencia, causalidad, evidencia, relevancia y empatía, con el objetivo de desarrollar en los futuros docentes, la conciencia histórica y el pensamiento histórico.

En el mismo contexto a través de lo propuesto por los anteriores investigadores, Mora y Ortiz (2011) elaboraron un Modelo Educativo y de formación, basado en la interacción de fuentes históricas, ellos consideran que esta visión alternativa a la enseñanza transmisiva es transformadora para impartir sesiones de historia. El modelo se concentra en el desarrollo de cuatro habilidades docentes: a) la transposición o dominio de fuentes e historiografía; b) la transferencia o diseño de secuencias didácticas; c) enseñanza estratégica o capacidad para realizar dichas secuencias superando los problemas emergentes de la clase y d) la docencia reflexiva.

A partir de estas investigaciones delimitamos la estrategia metodológica que nos permitió reflexionar con nuestros pares, los docentes de educación básica, sobre sus conocimientos previos de la conquista de México dado que es un contenido histórico que está presente en los actuales Programas de Estudio de Primaria.

El propósito central de este trabajo es explorar los conocimientos previos sobre el tema de la Conquista de México, con los conceptos: Conquista Militar y Conquista Espiritual y después confrontarlos con fragmentos de fuentes escritas que departen sobre el tema. Retomar a los docentes como foco de la investigación es porque sabemos que ellos son una de las piezas fundamentales en la educación.

\section{Materiales y Método}

En esta actividad participaron 22 profesores de educación primaria de escuelas ubicadas en el municipio de Temoaya y Otzolotepec, Estado de México, que actualmente están laborando con grupos de cuarto o sexto grado; se decidió elegir a dichos maestros porque el tema "La conquista de México" está completamente relacionado con aprendizajes que llevaron a cabo con sus alumnos en el transcurso de estos grados escolares. El contexto escolar de los 6 centros de trabajo es de organización completa. 
Se empleó la etnografía, con la cual se recuperó información detallada a través de sus instrumentos como la observación participante, la conversación y con registros de las actividades que los docentes expresaron y plasmaron en el material que se llevó a la sesión dentro de las instituciones educativas. La investigación es de corte cualitativo, ya que bajo una técnica de análisis del contenido de la información (imágenes pictográficas y videos de la sesión), se logró esquematizar en dos categorías definidas con los conceptos que se llevaron a los docentes, de donde también se realizó un balance sobre las similitudes que tenían los profesores, así como las diferencias que se promovieron durante el proceso de interacción que se tuvo con ellos.

Se realizaron sesiones basadas en la metodología de Julio Rodríguez Frutos (2000) sobre el proceso de modificación y reconstrucción en la enseñanza aprendizaje. Se trata de una actividad para reflexionar sobre el sentir y la actitud del docente al contrastar sus saberes previos sobre la conquista militar y espiritual en México, con fragmentos de tres fuentes escritas. De acuerdo con Cohen (2016), se entiende por saberes previos a "las herramientas que tiene (el sujeto) a disposición al establecer relaciones de significado en su interacción con la información formal para poder reconstruirla conceptualmente".

\section{Selección de fragmentos y clasificación de fuentes}

Para realizar el ejercicio con los docentes fue necesario antes hacer una selección de fragmentos de fuentes escritas la cual se desarrolló en tres momentos:

Clasificación. "Consiste en aprender a diferenciar el tipo de fuente según las distintas categorizaciones" (Valle, 2011) sabiendo que se dividen en dos grandes ramas, "las fuentes primarias se caracterizan por ser de primera mano, es decir, son contemporáneas a los hechos que se refieren, son directas (...); las secundarias son indirectas, fruto de una o más elaboraciones realizadas por otras personas, la fuente secundaria nos llega mediatizada por una o varias personas que elaboran una evocación o una reconstrucción del pasado a partir de los testimonios o de otros relatos” (Trepar, C. 1995: 195 como se citó en Reyes, 2017).

Al realizar un proceso de búsqueda y discriminación de fuentes, seleccionamos tres textos: Cartas de relación de Hernán Cortés y La historia verdadera de la conquista de la Nueva España de Bernal Díaz del Castillo como fuentes primarias, mientras que como fuente secundaria se retomó el libro 
Visión de los vencidos de Miguel León Portilla. Al dar lectura a las fuentes referidas la idea fue tener diferentes visiones historiográficas sobre la conquista de México.

Análisis de la fuente. Radica en "reconocer al autor, ubicarlo en su contexto histórico y comprender la información y el mensaje que transmite" (Valle, 2011). Las Cartas de Relación consisten en la explicación al emperador de España sobre lo que ocurría durante la conquista de este territorio, el caso de Bernal Díaz redactó de forma llana eventos donde fue actor o testigo de la conquista de México. Por otro lado, Miguel León Portilla investigador contemporáneo y amante del México antiguo, él mismo escribe en su obra que es un examen sereno del encuentro de esos dos mundos, el indígena y el hispánico, pero sin duda el libro está documentado en la imagen que se formaron las civilizaciones nativas y la lucha que hicieron durante la conquista.

Evaluación de las fuentes. "Permite comprender las posibilidades de información de una fuente a partir de su origen y propósito" (Valle, 2011), se logró seleccionar fragmentos sobre un mismo concepto que de acuerdo con Rodríguez (2000) "son los hechos o acontecimientos" de la historia; es por ello que se concluyó en indagar los conceptos de conquista militar y conquista espiritual que ocurrieron a partir del año 1519 en México.

\section{Estrategias de exploración.}

Para este estudio se consideraron dos fases del proyecto de procedimientos de Rodríguez (2000) (Tabla 1).

\begin{tabular}{|l|l|}
\hline 1. Introspección & 2. Proyección \\
\hline $\begin{array}{l}\text { Visualización o representación } \\
\text { visual. }\end{array}$ & Exposición del saber. \\
\hline Representaciones pictográficas. & $\begin{array}{l}\text { Diapositivas con fragmentos y } \\
\text { audios. } \\
\text { Conversación entre docentes. }\end{array}$ \\
\hline
\end{tabular}

Tabla1. Elaboración propia, a partir de Julio Rodríguez (2000).

La introspección de conocimientos previos, Rodríguez (2000) es aquella en la que a través de una estrategia de indagación de conocimientos, se le reconoce al sujeto con lo que sabe, es decir, ubicar los saberes ya sean vulgares, intuidos, de sentido común y/o académicos que posee cada individuo. 
Dicha fase se hizo con la estrategia: visualización o representación visual, en la que los docentes realizaron representaciones pictográficas sobre dos conceptos: Conquista Militar y Conquista Espiritual. Afirma el autor que la representación o visualización de conceptos, "es una operación de gran interés porque es una forma de explicación primitiva de lo que se ha comprendido" (p. 77).

La segunda fase de la investigación denominada proyección, asevera Rodríguez (2000) que es el momento donde al impartir una sesión el sujeto tiene la iniciativa exponiendo su saber, organizándolo de forma que se incluya a los otros. La idea es forzar el saber real trasladándole hacia un saber potencial, aun no reconstruido ni asimilado. Aquí el procedimiento consistió en la presentación de fragmentos que de manera cautelosa se seleccionaron de las tres fuentes escritas.

El tema de la conquista de México es muy amplio, por lo cual, se optó por indagar sólo en los dos conceptos antes mencionados, con la intención de que el docente reflexionara y contrastara sus conocimientos e incluso sus creencias personales con fuentes escritas, desde la tesis de que lo sucedido en nuestro país no fue un expedición pacifica por parte de los españoles, e intentamos con esto, ofrecer una réplica a lo expresado por Dussel (2019) que se habla del descubrimiento [de América] como un gran hecho y no como una conquista, la cual provocó diversas atrocidades tales como el genocidio. Esta fase propició una conversación, en la cual, se logró identificar las reacciones de los docentes cuando se les presenta información que contrapone, cuestiona o profundiza su saber en cuanto a sus conocimientos de contenidos de historia de México.

\section{Resultados}

\section{Fase de Introspección}

Esta actividad fue realizada en un espacio libre y ameno dentro de las escuelas, al docente se le entregó una hoja dividida a manera de tríptico, en donde se le indicó que dibujara lo que viniera a su mente sobre los conceptos de Conquista Militar y Conquista Espiritual, la indicación fue precisa de no escribir oraciones ni descripciones, ya que la estrategia de visualización se dedica específicamente a representaciones pictográficas que los sujetos pueden hacer, con base en los conocimientos previos que tengan sobre el concepto. Con relación a la introspección del concepto de conquista militar, es importante resaltar que en la mayoría de sus representaciones, los docentes manifiestan la diferencia en las herramientas de guerra y de otros elementos que se empleaban en las batallas entre las civilizaciones del México antiguo y los españoles. El docente expresa en sus 
dibujos (Figura 1), que por parte de las civilizaciones mesoamericanas los objetos de guerra eran flechas, hondas o rocas, así como una de las herramientas más importante por nuestras civilizaciones en los combates de hombre a hombre que era el Macuahuitl.

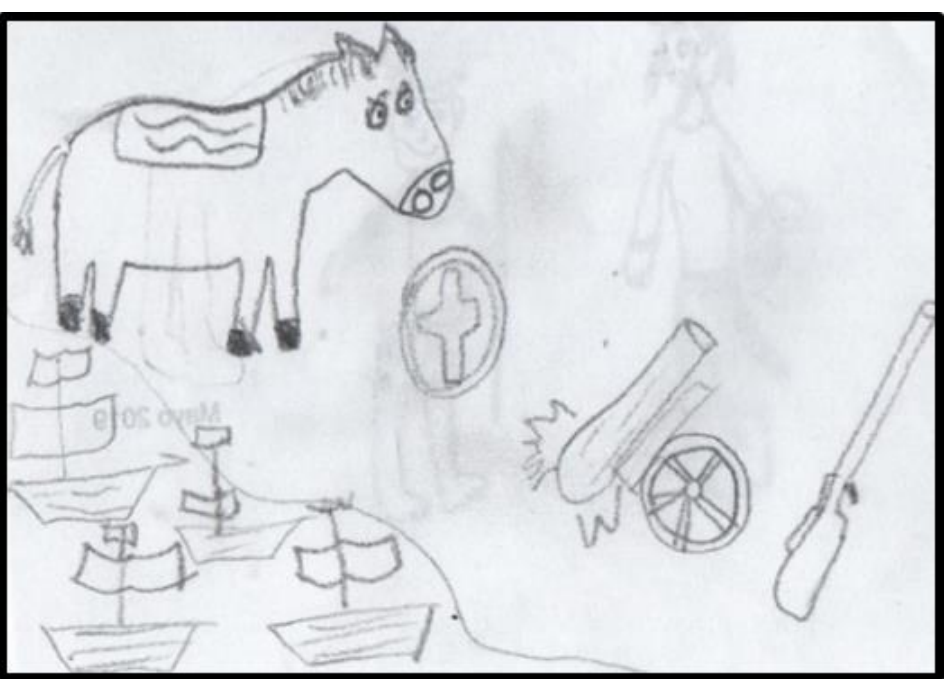

Figura 1. Objetos de guerra Mesoaméricanos

Se destaca en otra de las representaciones el empleo de las canoas, avance tecnológico que consideramos de suma importancia tanto en el desarrollo de la civilización Mexica, así como para la defensa de México-Tenochtitlan. En este sentido los maestros enfatizaron en el avance tecnológico en armas con que contaban los españoles en ese momento histórico. También, exponen en sus dibujos (Figura 2), armas de fuego, espadas, cañones, escudos y dos elementos más que se pueden considerar fundamentales para que se lograse este proceso, el empleo de los caballos que fueron de gran impresión para los nativos de estas tierras, ya que no se conocían, y los barcos. 


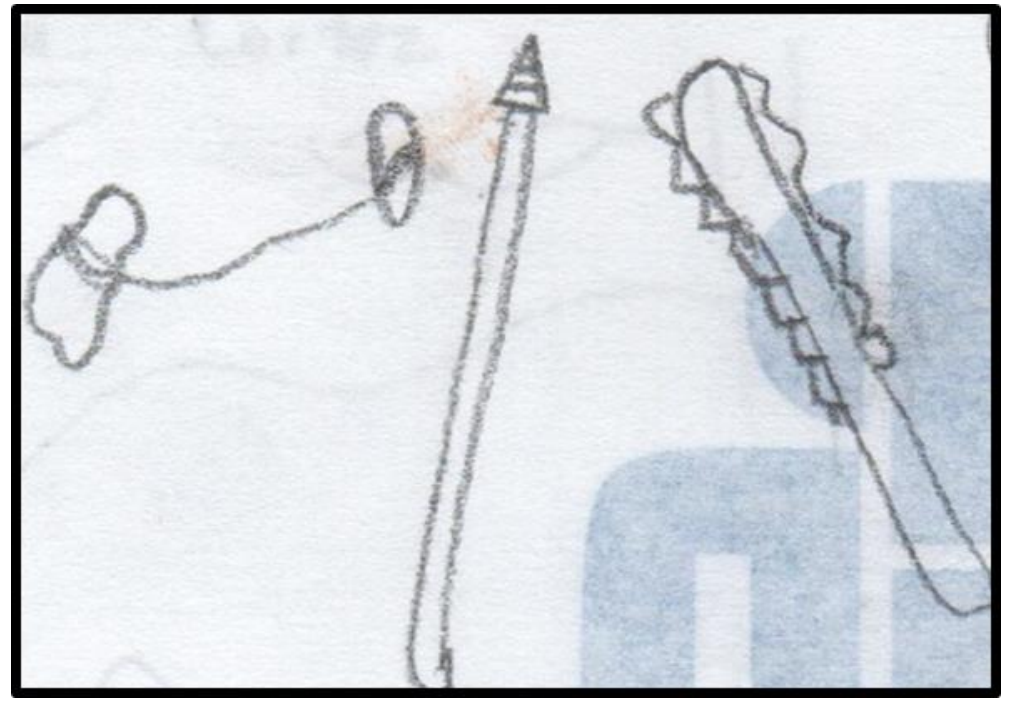

Figura 2.Elementos de guerra de los españoles

En las representaciones se expresa la diferencia de vestimentas entre nuestras civilizaciones y los españoles; a los primeros los dibujaron con una especie de taparrabos, lo que podemos considerar como un maxtlatl y sus característicos adornos de guerra como son las plumas, aunque en un solo dibujo se notó claramente esta especie de casco o sombrero tradicional de los guerreros que tenía forma de animales. Por otro lado, a los españoles se denota la portación de una armadura metálica, que sin duda fue una ventaja para ellos durante las batallas.

Un elemento recurrente y totalmente expresivo que es importante enfatizar, es que en las representaciones de los docentes, las imágenes hacen alusión a lo sangriento de las batallas que ocurrieron en ese momento histórico; pocos muestran a la conquista de México como un proceso pacífico. En dos producciones se plasmaron imágenes que ilustran las riquezas en oro y otros metales que se encontraban en estos territorios, así como la idea que tenían los dos grupos contrarios, por un lado, los nativos pensando en seres celestiales, mientras que los españoles se idealizaban por los grandes caudales en metales valiosos que nuestros antepasados portaban.

Solo en una expresión pictográfica se logra representar el recorrido que Hernán Cortés hizo a partir de 1519, es decir, el dibujo muestra la llegada en barcos a la costa de Veracruz y con flechas el avance que se hizo hacia México - Tenochtitlan, es de suma relevancia escribirlo porque durante aproximadamente dos años que dura este recorrido, es donde Hernán pone de manifiesto su estrategia militar para combatir a las civilizaciones del México antiguo. También es necesario 
mencionar que no se representa el apoyo y/o unión de otros pueblos para realizar la conquista de ese territorio.

Con la estrategia militar que planteo Cortés para realizar el cerco a México-Tenochtitlan, ningún maestro plasmó algo referente a ello, por ejemplo, a la construcción de bergantines para atacar mediante el lago a los mexicas o la destrucción del acueducto de Chapultepec, es decir, la mayoría de los dibujos solo se refieren a la diferencia armamentísticas y las batallas que se dieron durante el proceso.

Mencionar por último, con el concepto conquista militar, pocos docentes plasmaron un mapa del México antiguo, por lo que sería difícil deducir si los docentes consideran que la conquista de México solo se cierra a las batallas que tienen relación con la civilización Mexica o reconocen que nuestro territorio estaba integrado por más civilizaciones, tanto en el norte del país, como en el sur y que este proceso se llevó a cabo en los años posteriores. Ahora bien, con respecto a la conquista espiritual se logran rescatar símbolos significativos tanto para las civilizaciones pasadas, así como para la religión trasladada por los españoles a nuestras tierras.

Refiriéndonos a la religiosidad que se tenía por las civilizaciones nativas, los docentes (Figura 3), plasman los dioses que se les daba tributo como lo son: el sol, la luna, la lluvia, el viento, así como Quetzalcóatl o la serpiente emplumada. También expresan la adoración que se le tenía a la naturaleza y a sus cosechas como es el maíz.

Figura 3. Dioses del México Antiguo

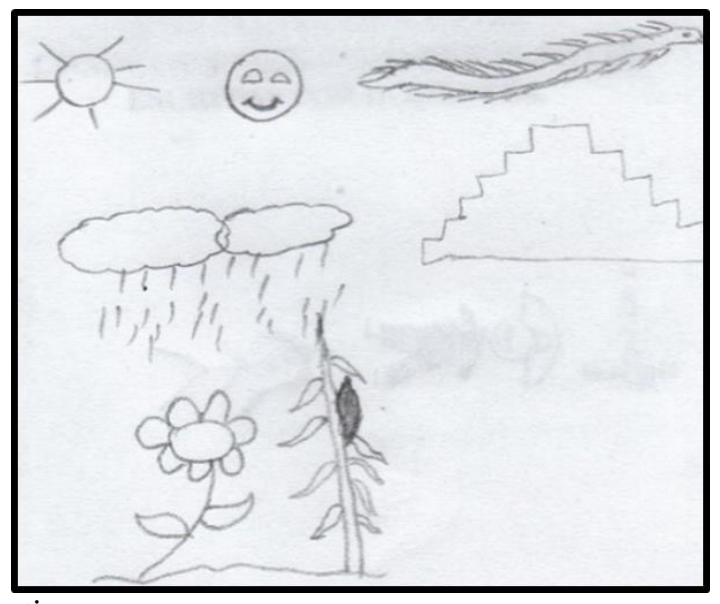


Algo muy importante en la representación, son las grandes construcciones que se realizaron en aquel momento histórico por nuestros antepasados, como las pirámides y los dibujos de monolitos semejando a estos dioses que construían los pobladores del México antiguo. Lo sobresaliente en la representación de un docente es la expresión del baile y el sacrifico humano que era parte fundamental de la religiosidad y el tributo a los dioses antepasados; fenómeno que causó tanto espanto y asombro en los conquistadores.

Haciendo alusión al simbolismo religioso de los españoles, los docentes muestran elementos relevantes, y los de mayor coincidencia son: la cruz, la biblia, la virgen, la iglesia y los conventos, así como frailes o personas dedicadas a la propagación de su religión. Observamos (Figura 4), la estrategia de destrucción o sepultura de pirámides y ahí mismo realizar la construcción de iglesias.

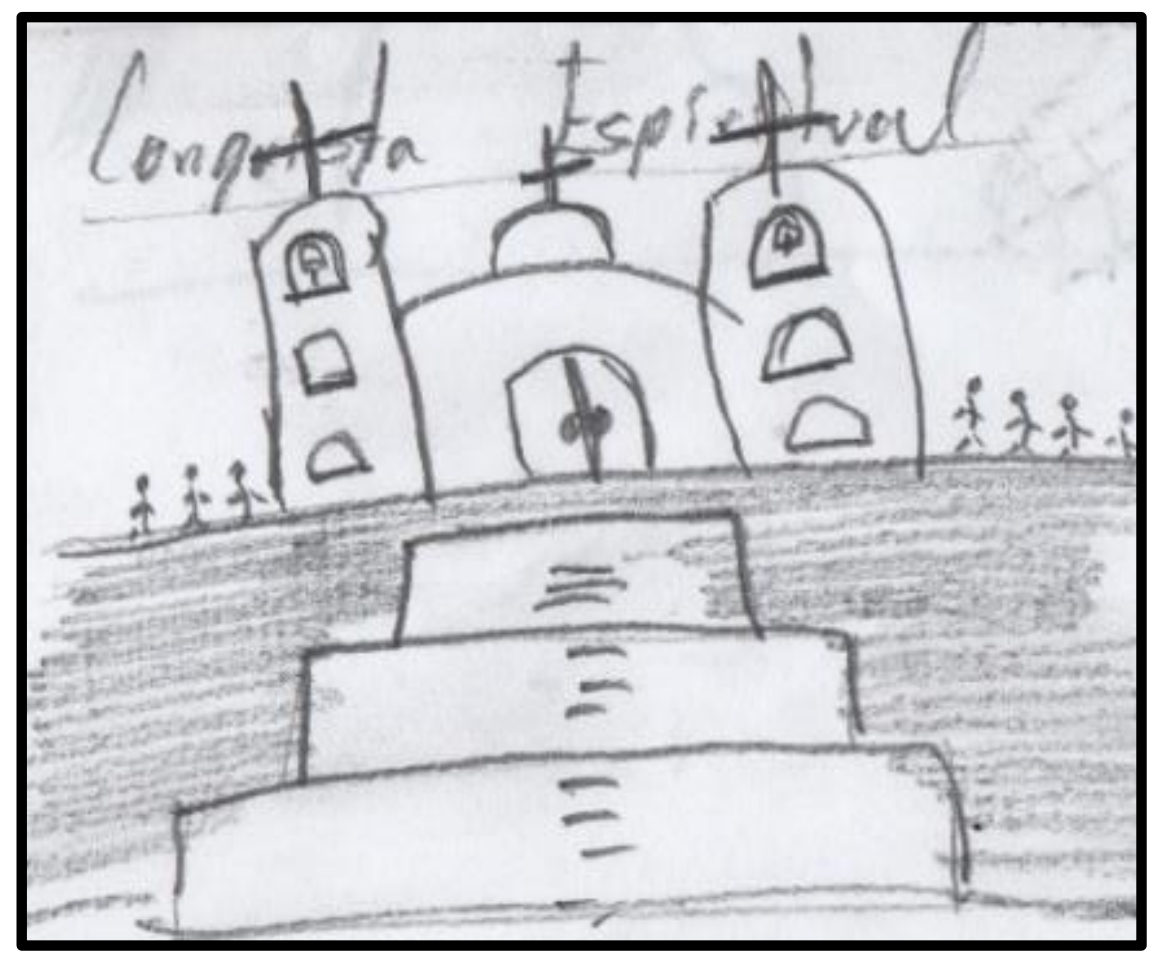

Figura 4. Construcción de Iglesias

Un proceso reproducido de diferentes formas por los maestros, es la evangelización desde dos puntos de vista: Algunos dibujan un proceso pacífico donde un fraile está conversando con personas en una especie de clases de religión; otros por el contrario, describen la obligación de 
adorar a otros dioses y en caso de negarse tener consecuencias radicales como los golpes o la muerte.

Al inicio de la actividad los docentes mostraron temor e incertidumbre, se notaban dudas al empezar a expresar sus ideas mediante dibujos, aunque también se mostraban expresiones negativas "a mí no me gusta la historia, no espere mucho de mí", por otro lado otros docentes que se reconoce que tienen la habilidad de dibujar, de manera decidida empezaron a elaborar sus representaciones, posteriormente en cuanto avanzó el desarrollo de la actividad los docentes de manera general se fueron desenvolviendo con mayor tranquilidad y participación.

Una situación que hay que mencionar es que al elaborar los docentes sus dibujos estuvieron modificando de manera inmediata, es decir, se contextualizaban a la época histórica que abarcaba el tema para que sus representaciones fueran de acuerdo al tiempo histórico. Ejemplo de ello fue que un docente expresó "en esa época no había campos militares" con respecto a la conquista militar.

\section{Fase de Proyección}

Con apoyo de las Tecnologías de la Información y la Comunicación (TICs), se proyectaron 6 diapositivas divididas en los dos conceptos planteados en la primera etapa. Las diapositivas contenían fragmentos de las tres fuentes escritas ya mencionadas con anterioridad, además de agregar el audio de la misma lectura, se decidió realizar este modelo de presentación porque al ser relatos históricos es necesario dar buen ritmo y volumen a los diferentes textos.

Los docentes mostraron una actitud positiva y de interés en la proyección, los fragmentos fueron en orden, primero el concepto de conquista militar y posteriormente conquista espiritual. Las fuentes escritas se presentaron primero Cartas de Relación, después Historia verdadera de la conquista de la Nueva España y por último la Visión de los vencidos. Así mismo se recuperan los comentarios que ellos expresaron.

Con la conquista militar los docentes hicieron alusión a que sus dibujos tienen relación con las acciones que están en los fragmentos de los libros; una de sus expresiones fue: “-La tecnología que tenían los españoles no se podía comparar con la de los Mexicas y prácticamente fue una 
masacre", esto lo dijeron porque en sus dibujos se nota la diferencia en las armas para la guerra de los dos grupos contrincantes.

Con referencia a la amplitud de los conocimientos que provocó en el docente la actividad, se rescata el comentario de una maestra: "-De alguna manera yo amplié un poco más mi conocimiento, no tenía la noción, la idea de la forma en que escriben los hechos" como esta expresión en su mayoría los docentes hicieron alusión a que se generó una amplitud de saberes, como por ejemplo: "-Sí complementaría mis dibujos después de la proyección (...), por ejemplo que en la conquista militar también sufrieron mujeres y niños". Aquí el docente deja claro que la información de la proyección desarrolló sus conocimientos.

Por el lado de la conquista espiritual agregaron su pensar, que difícilmente se pudo plasmar en el dibujo: "-La religión era para conquistarnos porque no podían de otra manera (...) nos metieron la adoración a la Virgen María", otro más expresó que con la llegada de los españoles entró a nuestro territorio la nueva religión "eso no era de aquí (...) la virgen y la cruz".

Con este concepto el tema lo trasladaron con la realidad, refiriéndose a las creencias que existen en las comunidades donde trabajan: "-Es difícil decir las cosas que pasaron, porque los niños creen en la religión que sus padres les han inculcado", también dicen que en ocasiones vierten comentarios contradictorios para que los niños indaguen que dioses había antes de que llegara el cristianismo a México.

Ahora, con lo que se desconocía de los fragmentos de las tres fuentes escritas también hubo comentarios de los docentes, que reflejan el proceso de evaluación de la fuente el cual se dio al tener un acercamiento a fuentes con diferente visión historiográfica, así que hubo varios enfoques en sus expresiones.

Los docentes expresaron su asombro ante la forma en que se describe la conquista por parte de las tres fuentes escritas y era algo que ellos desconocían: “-Si complementó lo que viene en la proyección, la manera en que ellos expresaban, como relataban, es algo que para mí era ajeno, algo nuevo", también dicen algunos docentes desconocer las fuentes escritas proyectadas: "-No conocía los tres libros y escuchar los audios me llamó mucho la atención porque es un tema muy enriquecedor y muy amplio, hay mucha información y a veces solo nos centramos en el libro" 
Algunos docentes refirieron la sensación que les provocó la proyección de los datos, un docente comentó: "-Ahorita al leer los fragmentos que aparecieron se hace interesante, porque como es la lectura, te remonta a ver o imaginar cómo suceden las cosas" otro más también dijo que solo había visto los libros como el de Cartas de Relación de Hernán Cortés, pero que a través de la actividad ahora le llamaba la atención para leerlo.

Significativo en el desarrollo del dialogo entre docentes, fue la actividad de contrastación de las tres fuentes escritas, ya que algunos mostraban cierta inclinación hacia algún libro de los conquistadores por la manera de describir los hechos, otros hacia la visión de los vencidos por apropiarse el sentir de las civilizaciones del México antiguo, otros más hicieron un balance de los tres textos.

Los que mostraron interés por las Cartas de Relación de Hernán Cortés, expresaban lo propicio que es conocer las descripción de los acontecimientos desde la persona que estaba al frente de la conquista: “-Con la lectura si se imagina porque está bien detallada" otro docente agregaba "me genera inquietud (...) observando algunos fragmentos, porque yo creo que es lo que más nos aproxima a la realidad, se pueden decir muchas cosas, pero ahí, siento que nos sintetiza de una forma clara la situación" aunque hubo maestros que diferenciaron con esta fuente "vi una versión corta, solo un reporte militar"

Por el libro de Bernal Díaz del Castillo los comentarios fueron escasos ya que lo ven como una fuente con una perspectiva neutra, porque consideran que no describe de manera radical o contundente los sucesos militares y espirituales que ocurrieron durante la conquista de nuestro territorio, un docente expresó: "-Todo lo hace ver como si la conquista fue de forma pacífica" tras el comentario una maestra añadió: "-Ninguna conquista se dio por la paz", en ocasiones durante la conversación los docentes coincidían en sus comentarios, aunque en otros casos mostraban diferencias.

La última fuente que se proyectó fue la Visión de los vencidos, con la cual se observó que en los docentes motivó el interés: “-Tiene más sentido de lo que realmente pasó" aunque también hubo un docente que disintió dicho comentario: "-Vamos a ver el contrapeso, nos interesa más el de los vencidos, porque somos mexicanos, fuimos parte de los vencidos", con esto podemos decir que el tema provoca un conflicto cognitivo y hasta psicosocial entre docentes. 
Hubo docentes que coincidieron en que existe concordancia entre las tres fuentes: "Prácticamente los tres autores hablan de lo mismo desde posturas diferentes" otro más comentó: “-Hay tres visiones del tema, pero todas coinciden, obviamente cada quien lo ve a su manera o perspectiva"

Algo importante del contraste de las fuentes fueron las conclusiones que los docentes refirieron: “-Hay demasiada información que nos ayudaría muchísimo en nuestra labor y quedaría más significativo [para los alumnos]" algunos docentes expresaron que en la labor no se la dan otras versiones a los estudiantes como el ejercicio que se realizó con ellos.

Al proyectar tres fuentes, los docentes se dieron cuenta de que es necesario el conocimiento de fuentes históricas para poder impartir un tema de historia, por lo que los maestros expresaron que "-Es necesario leer más" cuando otros mencionaron que se debe de indagar o investigar sobre los contenidos que se tienen que abarcar en la asignatura de historia, aunque algunos refutaron con una autocrítica sobre sus prácticas "-Como docentes nos falta, no hacemos lo que a veces le pedimos a nuestros alumnos: investigar, indagar y traer algo diferente".

Los docentes comentaron la falta de conocimiento y que es necesaria la lectura de varias fuentes para poder impartir un tema histórico "-Buscar otras fuentes que contraste con lo que sabe el niño, con lo que viene en el libro para lograr un aprendizaje significativo", también que no es suficiente con buscar, sino leer, analizar y dominar un tema para que después se pueda compartir con los alumnos, agregan que es necesario que "-Nosotros como docentes nos cultivemos más en estos temas".

\section{Conclusiones}

El empleo de fuentes escritas en la enseñanza de la historia no está en duda, con ellas el alumno y docente podrán profundizar en el contenido histórico. Pero el educador que retomará una fuente escrita, como explica Reyes (2017) tendrá que hacer antes "una lectura minuciosa de las obras, para no cometer errores que puedan empañar su manejo como fuente del conocimiento histórico; esto implica que tiene que dominar el contenido a tratar para saber en qué momento y cómo utilizarlas", logrando con ello, que esta fuente después de ser solo un texto, sea transformada en una fuente didáctica. 
Con fundamento en la investigación presentada, se logra fortalecer la idea de que es necesario el acercamiento y lectura de fuentes escritas entre los docentes, lo expresamos porque es fundamental que por cada tema histórico, el profesor tenga conocimiento de varias fuentes de información y así tener diferentes visiones historiográficas de un mismo hecho, para poder lograr un análisis donde se observe qué aportan las fuentes, viendo que tan razonables u opuestos son los textos.

Es importante descubrir cuáles son los saberes del docente porque si consolidamos la visión de Barrón que sus conocimientos son producto de la "experiencia (...) y a partir de ésta construyen y reconstruyen sus prácticas en el aula" sería una tarea para la investigación educativa en nuestro país indagar más a fondo, para que a través de ellos podamos iniciar un proyecto partiendo de los sujetos que se encuentran frente a las problemáticas de la educación.

Se ha investigado en el empleo de fuentes primarias en la educación básica, así como en la formación de docentes, sin embargo, el involucrarse con docentes que ya están en servicio abre otra posibilidad de exploración que es necesario desarrollar con los propios maestros, para construir estrategias para el empleo de fuentes para la enseñanza de la historia en la escuela primaria. Es por ello, que expresamos la necesidad de formular proyectos de educación histórica que se trabaje en la formación de comunidades de indagación con docentes en servicio en contextos específicos.

Esta investigación que se dio a través del acercamiento al profesional de la educación, que se encuentra frente a las problemáticas de la enseñanza de la historia, fue de gran beneficio para nosotros y en su caso para otros investigadores para poder poner en el centro de la investigación a los docentes; realizar acercamientos que propicien un análisis de las perspectivas que tienen los profesores para la enseñanza de historia. Finalmente esta investigación nos permite diseñar proyectos de intervención al lado de nuestros pares, para poder promover propuestas que realmente se puedan ejecutar en la educación y dejar de lado el sistema jerárquico de intentar llevar a los docentes soluciones alejadas de sus problemáticas y potenciar las experiencias y saberes docentes.

\section{Referencias}

Arteaga, B. y Camargo, S. (10 de agosto de 2019). Educación histórica, una propuesta para el desarrollo del pensamiento histórico en los estudiantes de la licenciatura en educación 
preescolar $\quad y \quad$ primaria. $\quad$ Recuperado de https://www.dgespe.sep.gob.mx/public/comunidades/historia/recursos/educacion_historica_1 9_de_agosto_2012.pdf

Barrón, C. (2006). Los saberes del docente. Una perspectiva desde las humanidades y las ciencias sociales. Perspectiva Educacional, Formación de Profesores, (48), 11-26.

Cohen, Liliana. (2016). Los conocimientos previos en el proceso de aprendizaje de contenidos históricos en el contexto escolar. Revista Didácticas Específicas. 15. 28-50.

Cortés, H. (2018). Cartas de relación. México: Porrúa.

Díaz, B. (2017). Historia verdadera de la conquista de la Nueva España. México: Porrúa.

Dussel, E. [paraleerenlibertad]. (2019, Abril 29). "La conquista de México" [Archivo de video]. Recuperado de https://www.youtube.com/watch?v=sDkF1Q9YhPo

León, M. (2005). Visión de los vencidos. México: Editores e Impresores FOC, S. A. de C. V.

Mora, G. y Ortiz, R. (12 de septiembre de 2019). Modelo de Educación Histórica. Recuperado de http://www.ub.edu/histodidactica/images/documentos/pdf/modelo_educacion_historica.p df

Reyes, J. I. (enero-febrero, 2017). Encuentro Internacional por la unidad de los educadores. Fuentes para enseñar y aprender la historia. Pedagogía 2017, 31, 16-28.

Rodríguez, J., Aróstegui, J., Campuzano, A., Pagés, J., Valdeón, J., y Rodríguez, A. (2000). Enseñar historia. Nuevas propuestas. México: Editorial Laia, S. A.

Valle, A. (05 de abril de 2019). El uso de las fuentes escritas en la enseñanza de la Historia. Análisis de textos escolares para tercero y cuarto de secundaria. Recuperado de http://revistas.pucp.edu.pe/index.php/educacion/article/view/2604/2552 